\title{
Comunidade escolar de Mato Grosso do Sul: refletindo sobre o trabalho de docentes do gênero masculino
}

\author{
School community of Mato Grosso do Sul: reflecting the faculty of work gender male
}

Comunidad escolar de Mato Grosso do Sul: refleja el trabajo de los profesores varones

\author{
JOSIANE PERES GONÇALVES* \\ EDICLEIA LIMA DE OLIVEIRA**
}

\begin{abstract}
RESUMO
O presente estudo tem por objetivo identificar as representações sociais de professores homens, gestores escolares e familiares de alunos de educação infantil e anos iniciais do ensino fundamental do município de Corumbá (MS), em relação ao trabalho desenvolvido por docentes do gênero masculino com crianças. A metodologia consiste na gravação de entrevistas semiestruturadas, posteriormente transcritas, sistematizadas e analisadas. Participaram do estudo dez pessoas, sendo cinco da educação infantil e cinco dos anos iniciais do ensino fundamental. Os resultados revelam que nos dois níveis de ensino averiguados não há grandes problemas relacionados ao trabalho desenvolvido pelos professores homens em Corumbá. Entretanto, o medo do que a família vai pensar e as representações sociais de que a mulher é a pessoa mais adequada para cuidar e educar as crianças na escola exercem influências para que exista um número cada vez menor de docentes do gênero masculino trabalhando nas duas primeiras etapas da educação básica.
\end{abstract}

Palavras-chave: Gênero. Docência. Educação infantil. Ensino fundamental.

\begin{abstract}
This study aims to identify the social representations of male teachers, school managers and family of early childhood education students and early years of elementary school in the city of Corumbá (MS), in relation to the work of male teachers with children. The methodology consists of the recording of semi-structured interviews, which were later transcribed, systematized and analyzed. The study included a total of ten people, five of early childhood education and five of the early years of elementary school. The results indicate that in both investigated levels of education no major problems related to the work of the men teachers in Corumbá. However, the fear of what the family will think and social representations that the woman is the best person to care for and educate children in school exert influence so that there is an ever-decreasing number of male teachers working in the first two stages of basic education.
\end{abstract}

Keywords: Gender. Teaching. Child education. Elementary School.

\begin{abstract}
RESUMEN
Este estudio tiene como objetivo identificar las representaciones sociales de los profesores varones, directores de escuela y familiares de los alumnos de educación infantil y primeros años de la escuela primaria en la ciudad de Corumbá (MS), en relación con el trabajo de los profesores varones con los niños. La metodología consiste en la grabación de entrevistas semiestructuradas, las cuales posteriormente fueron transcritas, sistematizadas y analizadas. En el estudio participaron un total de diez personas, cinco de la educación infantil y cinco de los primeros años de la escuela primaria. Los resultados indican que en ambos investigó los niveles de enseñanza principales problemas relacionados con el trabajo de los maestros hombres en Corumbá. Sin embargo, el miedo a lo que la familia va a pensar y representaciones sociales que la mujer es la mejor persona para cuidar y educar a los niños en la escuela ejercen influencia para que haya un número cada vez menor de los profesores varones que trabajan en los dos primeros etapas de la educación básica.
\end{abstract}

Palabras clave: género. Enseñanza. Educación infantil. Enseñanza fundamental.

\footnotetext{
*Doutora em Educação pela Pontifícia Universidade Católica do Rio Grande do Sul (PUCRS). Professora do Programa de Pós-graduação em Educação pela Universidade Federal de Mato Grosso do Sul Campus do Pantanal (UFMS/CPAN) e do Programa de Pós-Graduação em Educação pelo Centro de Ciências Humanas e Sociais (UFMS/CCHS). Líder do Grupo de Estudo e Pesquisa em Desenvolvimento, Gênero e Educação (GEPDGE). E-mail: <josianeperes7@hotmail.com>.

**Graduanda do Curso de Pedagogia da UFMS. Bolsista de Iniciação Científica CNPq. E-mail: <edicleia.oli1@gmail.com>.
} 


\section{INTRODUÇÃO}

$\mathrm{Na}$ atualidade, as discussões relativas a gênero se voltam mais para a compreensão de fenômenos inerentes ao universo feminino e pouco se aborda sobre o masculino, porque, historicamente, os estudos a esse respeito estão relacionados ao avanço do movimento feminista, conforme observa Louro (1999). No caso da educação escolar, não é diferente, visto que normalmente as pesquisas se referem ao trabalho de professores como um todo, ou especificamente ao trabalho educativo desenvolvido por mulheres.

Isso ocorre porque existem poucos professores homens trabalhando na educação básica, principalmente quando se trata de crianças em que se associa o cuidar e o educar, tornando-se cada vez mais difícil encontrar homens que optem pela profissão do magistério. Aí surge a necessidade de se analisar quais são os elementos que contribuem para tal realidade.

De acordo com Jardim (2003, p. 27-28), “a educação escolar é um campo que vem sendo conquistado por movimentos sociais na busca de igualdade de direitos e de oportunidades e, portanto, de superação de descriminação". Essa busca por igualdade de direitos inclui as relações de gênero, uma vez que a intersecção entre este e a educação colabora para a assimilação de que a convivência entre as diferenças é permanente na formação social e cultural dos indivíduos. Para a autora, a escola tem papel fundamental na formação das pessoas:

A escola é aqui entendida como uma das instituições que normatiza, disciplina e distribui formas e jeitos de ser, sendo um dos espaços de formação, de produção e reprodução de saberes e de poderes. Assim, a escola é uma das instituições na qual o indivíduo é produto do poder e do saber e, ao mesmo tempo, é atravessado por eles (2003, p. 28).

É evidente que a escola faz parte de um contexto histórico-cultural, e a instituição escolar recebe grandes influências da sociedade, sendo um local onde se produz e, principalmente, reproduz-se conhecimento, inclusive no que se refere às questões de diversidade.

No caso das relações de gênero, Trindade (2005) ressalta que, durante muitas décadas, elas foram pensadas somente para o público feminino, sendo menosprezada a busca de conhecimento voltada à compreensão dos problemas masculinos. A justa preocupação com as condições femininas possibilitou o surgimento de espaços privilegiados para as mulheres como inspiradoras de problemas de pesquisa, sendo negligenciada essa mesma possibilidade aos homens, por se entender que eles já eram produtores sociais de conhecimento. Como consequência, na atualidade, é possível ser encontrado um vasto material sobre feminilidade, enquanto, sobre a masculinidade, quase não há produções científicas.

Para Coelho e Carloto (2007), os estudos sobre masculinidade surgiram com maior intensidade a partir da década de 1990, devido a preocupações com a saúde masculina. Assim, os homens passaram a ser vistos como objeto de pesquisa e não somente como produtores de conhecimento. Connell (1995), seguindo posições prófeministas e sendo considerada precursora dos estudos sobre masculinidade, acredita que é preciso investir na produção de conhecimento sobre masculinidade, também como ferramenta que permite criar melhores condições para enfrentar as injustiças que permeiam as relações de gênero. Se, na sociedade, apenas as mulheres eram consideradas sujeitos de pesquisa, na escola não foi diferente. Rabelo (2013) afirma que há alguns anos se percebe uma grande quantidade de pesquisas unindo profissão educacional às perspectivas de gênero, porém estas têm como foco o estudo da categoria representada pelas mulheres, sem considerar que a feminização produz uma generificação da profissão que atinge também os professores homens.

Santos (2007) ressalta que os gêneros masculino e feminino podem ser compreendidos como composições sociais que se alteram mediante o espaço, a cultura, o tempo, o passar da vida de cada indivíduo e na relação entre diferentes grupos de acordo com a sua classe, raça, idade e ética. Para Scott (1998), gênero é:

\section{A organização social da diferença sexual. Ele não reflete a realidade biológica primeira, mas ele constrói o sentido desta realidade. A diferença sexual não é a causa originária da qual a organização social poderia derivar; ela é, antes, uma estrutura social móvel que deve ser analisada nos seus diferentes contextos históricos (SCOTT, 1998, p. 15).}

Não há dúvidas de que, em qualquer profissão escolhida, dificuldades sempre serão encontradas, porém na área da docência, principalmente na educação infantil e nos anos iniciais do ensino fundamental, professores homens enfrentam muitos obstáculos e preconceitos. Tal pressuposto é perceptível no pensamento de Rabelo (2013), que, ao desenvolver uma pesquisa com professores homens do Brasil e de Portugal, constatou:

Os preconceitos que mais apareceram foram aqueles relacionados com: a homossexualidade (homofobia); a concepção de que o homem é incapaz de lidar com crianças (por exemplo, por ser diferente, jovem, indelicado, autoritário); o pressuposto de que todos/ as os/as professores/as do segmento são mulheres ou de que se trata de um trabalho feminino; o medo da pedofilia e do assédio sexual; a consideração de que a docência é um ofício pouco rentável e não 
adequado para homens. Também foram citadas outras discriminações, como o preconceito racial, a discriminação positiva e a exclusão de decisões (RABELO, 2013, p. 912).

Diante de tal fato, é notável um grande receio em relação ao trabalho do homem professor; no entanto, compreender que mulheres e homens podem desenvolver papéis simultâneos é um grande passo para que esse conceito possa mudar. Nesse sentido, Jardim (2003) enfatiza:
A luta não se dá apenas pela igualdade. Consiste numa fase em que a luta se dá pela afirmação e pela valorização da diferença. Ou seja, as propostas visam ir além da igualdade entre homem e mulher, têm por objetivo a multiplicidade. Essa preocupação inova os estudos de gênero que são atravessados pelas linhas de classe, de raça, de etnia, de opção sexual e outras (JARDIM, 2003, p. 24).

De acordo com Pincinato (2004), referir-se ao magistério como ofício é construir um saber acerca do que é uma profissão, como são entendidas a feminilidade e a masculinidade em nossa sociedade e atribuir valores sociais a esses gêneros. Sendo assim, as diversidades sexuais foram deslocadas para a execução de funções, enchendo a docência de conceitos femininos, relacionando-a à maternidade e ao cuidado com as crianças e, por outro lado, atribuindo cargos administrativos ao sexo masculino, associado a posturas mais rígidas e autoritárias.

Tais ideias evidenciam as representações sociais predominantes em relação aos gêneros feminino e masculino no espaço escolar. Para Moscovici (1973), o pioneiro dessa teoria, as representações sociais podem ser assim entendidas:

[...] um sistema de valores, ideias e prática com uma dupla função: primeiramente, estabelecer uma ordem que habilitará os indivíduos a orientarem-se em seu mundo material e social e dominarem-no; e, em segundo lugar, possibilitar a realização da comunicação entre os membros de uma comunidade pelo fornecimento de um código para o "intercâmbio" social e de um código para nomearem e classificarem, sem ambiguidades, os diversos aspectos de seu mundo e de sua história individual e em grupo (MOCOVICI, 1973, p. 17).

Ao refletir sobre as representações sociais, Oliveira e Werba (2003) advertem que estas alteram os indivíduos em seu contexto social e têm como papel moldar sua conduta e demonstrar suas manifestações. Além de organizar a operação, transformando e reconstituindo as situações do ambiente para que essa conduta se conserve. No caso das representações sociais sobre homens professores trabalhando com crianças, historicamente elas foram construídas no sentido de acreditar que as mulheres é que devem assumir essa função, por ser o trabalho docente associado com a maternidade.

Por tudo isso, destacamos que os estudos de gênero são importantes para a análise da presença dos homens em atividades socialmente consideradas femininas, pois o trabalho desses profissionais entra em conflitualidade com as expectativas e pode mostrar exceções aos padrões de gênero ou tentativas de reafirmação de sua masculinidade. Enfim, os estudos de gênero podem ajudar a compreender conflitos, resistências, reafirmações, satisfações e sucessos desses homens que parecem estar fora de lugar (RABELO, 2013, p.911).

Mediante o relato da autora, é evidente a desigualdade nas relações de gênero presentes na sociedade, principalmente quando diz respeito ao âmbito escolar. Ao atuar em uma profissão vista socialmente como feminina, os professores homens, independentemente de possuírem formação profissional para trabalhar com crianças, têm de provar quase o tempo todo que são aptos, tendo ainda de lidar com o preconceito de quem acredita que as mulheres é que têm maiores condições de serem professoras de crianças.

Sendo assim, o foco central deste estudo envolve o trabalho desenvolvido por docentes do gênero masculino, estando vinculado ao Grupo de Estudo e Pesquisa em Desenvolvimento, Gênero e Educação (GEPDGE) da Universidade Federal de Mato Grosso do Sul (UFMS). Esse grupo de pesquisadores vem realizando pesquisas sobre o trabalho de professores homens com crianças desde 2012. Desse modo, surgiu o interesse de entender como isso acontece em municípios que têm docentes do gênero masculino trabalhando com turmas de educação infantil e ensino fundamental. A opção foi Corumbá (MS), por se tratar de uma cidade que faz fronteira com outro país (Bolívia) e por estar distante da capital do estado.

Logo, este trabalho tem por objetivo investigar as representações sociais de professores homens, de gestores escolares e de familiares de crianças matriculadas em turmas de educação infantil e anos iniciais do ensino fundamental no município de Corumbá (MS).

\section{METOdOLOGiA}

O estudo caracteriza-se por uma pesquisa de natureza qualitativa. Ao refletir sobre esse tipo de pesquisa, Zanten (2004, p.31) salienta: “O trabalho de investigação qualitativa é entender globalmente as categorias que mobilizam os atores para compreender a realidade e para 
atuar sobre a realidade". Na área educacional, as pesquisas qualitativas são mais apropriadas, pois permitem uma melhor compreensão do ponto de vista do entrevistado. Sobre esse assunto, a referida autora afirma:

Nos estudos em educação, o caráter quantitativo não é tão grande e muitos não dominam o campo estatístico, os instrumentos quantitativos. Ao contrário, as pesquisas qualitativas the parecem tão familiares, tão próximas de sua própria maneira de pensar, que a interpretação sempre está muito mais aberta (2004, p. 31).

De início, foram realizados estudos e discussões pelos integrantes do GEPDGE sobre abordagem teórica e possibilidades de encaminhamentos para a realização da pesquisa de campo. Assim, foi feita a opção pela utilização de entrevistas a partir de um questionário apenas semiestruturado, visto que, para identificar as representações sociais dos participantes da pesquisa, esse tipo de instrumento era bastante eficaz.

As entrevistas semiestruturadas combinam perguntas abertas e fechadas, onde o informante tem a possibilidade de discorrer sobre o tema proposto. $\mathrm{O}$ pesquisador deve seguir um conjunto de questões previamente definidas, mas ele o faz em um contexto muito semelhante ao de uma conversa informal. $\mathrm{O}$ entrevistador deve ficar atento para dirigir, no momento que achar oportuno, a discussão para o assunto que o interessa fazendo perguntas adicionais para elucidar questões que não ficaram claras ou ajudar a recompor o contexto da entrevista, caso o informante tenha "fugido" ao tema ou tenha dificuldades com ele. Esse tipo de entrevista é muito utilizado quando se deseja delimitar o volume das informações, obtendo assim um direcionamento maior para o tema, intervindo a fim de que os objetivos sejam alcançados (BONI; QUARESMA, 2005, p.75).

Com base nessas convicções, foram produzidos roteiros semiestruturados para os diversos grupos de sujeitos, abordando a mesma temática, ou seja, as representações sobre o trabalho desenvolvido por professores homens com crianças. Ao utilizar esse tipo de estratégia, tornou-se possível que todos os entrevistados demonstrassem livremente seus pensamentos, experiências e representações sociais relacionados ao tema investigado.

A escolha pelo município de Corumbá ocorreu mediante contatos telefônicos feitos às Secretarias Municipais de Educação do estado de Mato Grosso do Sul pelos integrantes do GEPDGE. Ficou constatado que são poucos os municípios que têm professores homens trabalhando com turmas de educação infantil, mas em Corumbá havia o caso de um professor que já atuava há 16 anos, nessa etapa da educação básica. Além de atender aos critérios para a realização da pesquisa, o referido município foi visto como um espaço relevante de investigação, devido às suas características geográficas, históricas e culturais.

De acordo com Congro (2015), o município de Corumbá encontra-se situado a $420 \mathrm{~km}$ da capital, ao sul da região Centro-Oeste (MS). É a cidade mais antiga dessa região. Localiza-se próxima à fronteira com a Bolívia, à beira do rio Paraguai, sendo a última cidade brasileira antes do território boliviano. Com uma população de 108.656 habitantes, conforme dados do IBGE (2015), é um dos municípios mais populosos do estado. "Localizada na margem direita do rio Paraguai, a cidade oferece aos visitantes, em termos de atrações turísticas, belezas naturais exclusivas, biodiversidade de fauna e flora e expressivo patrimônio histórico e cultural" (CONGRO, 2015, p. 11).

Para a realização da pesquisa de campo, foi feito incialmente contato com gestores da Secretaria Municipal de Educação de Corumbá, que indicaram quais instituições de educação infantil e anos iniciais do ensino fundamental possuíam professores homens atuando como regentes. Assim, após ser agendado o dia para a realização da coleta de dados, de acordo com a disponibilidade das escolas, alguns integrantes do GEPDGE foram até Corumbá para gravar as entrevistas com os seguintes participantes da pesquisa:

1. Professor Homem da Educação Infantil (PH.EI): 64 anos de idade, formação em Pedagogia e mestrado (no Paraguai); atuante há 31 anos na educação e há 16 anos como docente de educação infantil.

2. Gestora Escolar da Educação Infantil (GE.EI): 49 anos de idade, formação em Magistério, graduada em Letras, especialista em educação infantil; atuante há mais de um ano como gestora da instituição investigada.

3. Gestora Municipal da Educação Infantil (GM.EI): 32 anos de idade, formação em Pedagogia, especialista em Psicopedagogia, atuante há cinco anos na educação infantil e há dois anos, na gestão municipal.

4. Familiares da Educação Infantil (F1.EI) - mãe de menino: 32 anos de idade, doméstica, com ensino médio completo.

5. Familiares da Educação Infantil (F2.EI) - tia de menino: 30 anos de idade, agente de saúde, com ensino médio completo.

6. Professor Homem do Ensino Fundamental(PH.EF): 35 anos de idade, formação em Pedagogia, licenciatura plena com habilitação em educação infantil, atuante há 14 anos na educação. 
7. Gestor Escolar do Ensino Fundamental (GE.EF): 33 anos de idade, formação em Letras, atuante há dez anos na educação e há três anos na gestão da investigada.

8. Familiares do Ensino Fundamental (F1.EF) - mãe de menina: 35 anos de idade, doméstica, com ensino fundamental incompleto.

9. Familiares do Ensino Fundamental (F2.EF) pai de menina: 30 anos de idade, motorista, com ensino médio incompleto.

10. Familiares do Ensino Fundamental (F3.EF) - pai de menino: 42 anos, afastado do trabalho, com ensino superior incompleto.

É importante destacar que os gestores escolares trabalhavam na mesma instituição de ensino que os professores homens investigados, e os familiares eram responsáveis por crianças que também estavam matriculadas nas turmas desses professores, tanto na educação infantil quanto nos anos iniciais do ensino fundamental.

\section{Resultados e Discussão}

Os resultados obtidos mediante a pesquisa de campo realizada com a comunidade escolar de Corumbá encontram-se assim organizados: primeiramente, são analisadas as representações sociais do professor homem, dos gestores e familiares de crianças da educação infantil, para, em seguida, analisar os dados dos anos iniciais do ensino fundamental. Nas considerações finais são estabelecidas relações entre as duas etapas da educação básica, buscando analisar se existem semelhanças e/ou diferenças nas representações sociais predominantes, a respeito do trabalho desenvolvido por docente do gênero masculino com crianças.

\section{Educação infantil}

Para que pudessem ser analisadas as representações sociais da comunidade escolar, levantaram-se questionamentos sobre a opinião que o docente do gênero masculino, e os gestores e familiares tinham em relação ao trabalho desenvolvido por professores homens com crianças de educação infantil. Sendo assim, o professor PH.EI declarou que, aos poucos e com muito trabalho, conquistou seu espaço, relatando suas impressões sobre as relações de gênero na sociedade e na escola.

“[...] as mulheres são machistas, elas acham que o homem, o guri, não pode brincar de boneca; falta a educação não sexuada. Ela acha isso, então ela acha que a mulher não pode isso, não pode aquilo, quando a mulher pode tudo! Tudo! É só dar preparo, como é para o homem, ensinar ele a trocar uma fralda e, se ele não vai aprender, ensinar ele como dar uma mamadeira, preparar uma mamadeira para dar à criança se ele não vai aprender, então ensinar da necessidade de se trabalhar. A pessoa tem que coisar para isso, espera, o cara tem que ser macho, mas o resto é um ser humano..." (PH.EI)

A gestora municipal ressalvou que não havia diferença entre o trabalho desenvolvido pelo professor do sexo masculino ou pelo do sexo feminino, porém ela comentou sobre o binômio cuidar/educar, que no caso do professor homem é realizado pela auxiliar de serviços diretos (atendente). As professoras mulheres se encarregam de cuidar e educar a criança. Mesmo assim, a GM.EI insistiu em dizer que não havia diferença na questão do sexo do professor de educação infantil. Afirmou também que ao observar o trabalho do professor homem com as crianças, percebeu que ele era cuidadoso, carinhoso e comprometido com o que fazia.

No caso da gestora da escola GE.EI, ela reconheceu que achou diferente encontrar um professor homem trabalhando com criança porque, segundo ela, pedagoga é sempre mulher. Tanto a gestora municipal quanto a gestora escolar sinalizaram o que pode ser entendido como um período comprobatório, em que os professores do sexo masculino, segundo Ramos (2011, p.61), “[...] precisam oferecer provas de idoneidade, competência, habilidade e, especialmente, de uma sexualidade que não ofereça riscos para as crianças". Uma das falas da gestora escolar deixa bem evidenciada suas representações a respeito desse assunto:

\footnotetext{
"[...] quando eu cheguei aqui, ano passado, que eu vim de outra instituição de educação infantil, eu também me deparei com ele... Eu achei diferente, né? Geralmente o pedagogo é mulher, né? E deparei com o professor, observei bastante ele e vi o quanto ele era querido pelas crianças. Ele faz um bom trabalho, sabe? A princípio, eu assustei mesmo, porque nós estamos acostumadas com pedagogas mulheres e até o próprio cuidar, aquela questão da higiene, entendeu? Tem todo um processo... Desde pequeno, geralmente, quem cuida é a mulher, né?” (GE.EI)
}

Os familiares das crianças demonstraram aparentemente não ter nenhum problema com o trabalho do professor homem. A F1.EI, por exemplo, argumentou que já havia encontrado professores homens na educação infantil. Já a F2.EI, no início, disse ser normal a criança estudar com um homem, mas no decorrer da entrevista ela se contradisse quando declarou: "Ué? Professor? Dando aula pra criança, né? Achei que era uma coisa, mas... assim, conhecendo ele, a gente percebe que é uma pessoa boa".

Pode-se entender esse estranhamento devido às representações predominantes na sociedade de que a 
mulher é quem deve cuidar de crianças, justificando a feminização do magistério. Ao se deparar com uma situação que fuja do padrão ao qual estão acostumados, os indivíduos demonstram estranheza, que, segundo o viés das representações sociais, é o medo do desconhecido, algo a que não estão habituados. Sá $(1995$, p. 37) afirma que "[...] o estranho atrai, intriga e perturba as pessoas e as comunidades, provocando nelas o medo da perda dos referenciais habituais, do senso da comunidade e de compreensão mútua". Arce (2001), em seus estudos, traz a confirmação desse pensamento, tratando desse conceito como um mito:

Trabalhando com esta acepção de mito, constatei, mediante estudos, que a constituição histórica da imagem do profissional da educação infantil tem estado fortemente impregnada do mito da maternidade, da mulher como a rainha do lar, educadora nata, cujo papel educativo associa-se necessariamente ao ambiente doméstico, sendo assim, particularmente importante nos primeiros anos da infância. $\mathrm{O}$ início da educação de todo indivíduo deveria, assim, ser uma extensão natural da maternidade. Cumpre, entretanto destacar que este mito da mulher mãe e educadora nata exerce seu maior poder orientador no período relativo aos anos iniciais da vida do indivíduo, não sendo atribuída à mulher a responsabilidade sobre a educação em geral (2001, p.4).

Todos os participantes da pesquisa de educação infantil foram indagados sobre a hipótese de haver duas turmas com a mesma faixa etária, uma sob o comando de uma professora mulher e outra sob o comando de um professor homem. Nesse caso, questionou-se sobre qual sala optariam os pais ou responsáveis. O PH.EI expôs que a sociedade é machista e que escolheria a mulher se fossem colocar uma filha, apesar de que ele já deu aula para várias meninas.

\footnotetext{
"Como eu falei, por causa de um complexo... Qual complexo? De que a sociedade é machista, a sociedade, tanto o homem quanto a mulher, acha que se for um homem trabalhar ali, a menina não vai aprender, vai ficar de lado. Mas, quando você trabalha, primeiramente você tem que ter respeito, tem que fazer com amor, respeito, carinho, afeto pra criança. Quando se tem respeito, você consegue fazer com qualquer pessoa, não só com a criança, o trabalho que você quer fazer, você alcança o objetivo." (PH.EI)
}

Em sua fala, o PH.EI enfatizou as representações a respeito do trabalho desenvolvido pelo homem professor especificamente com as meninas, pois na sociedade ocorre a ideia de que o homem não é "adequado" para lidar e ensinar as meninas, principalmente quando se refere ao cuidado e à higiene. Se for analisada a fala do professor, ele diz que não há problemas em trabalhar com meninas porque já deu aula para várias delas. Um fato curioso sobre a realidade vivida pelo professor durante a realização da pesquisa pode ser entendido por meio da fala da gestora escolar: "Só tem menino na turminha dele. Então, nada melhor do que ter homem para conduzir os homens". Um fato tanto quanto inusitado, em pleno século XXI, uma sala composta apenas por meninos, sendo que a convivência entre meninos e meninas é essencial para que a criança se desenvolva e estabeleça vínculos.

\begin{abstract}
Na educação infantil as crianças podem passar a maior parte do tempo em contato com outras crianças. É nessa relação singular que o protagonismo da criança ganha destaque e que a potencialidade do convívio, em suas diversas formas de relações, pode propiciar uma nova interação. Trata-se de um universo com características próprias, voltadas para crianças pequenas. Uma formatação com espaços, tempos, organizações e práticas construídos no seio das intensas relações entre crianças e entre crianças e adultos (VIANNA; FINCO, 2009 p. 270).
\end{abstract}

A respeito da opção por sala de homem ou de mulher, a gestora da escola revelou que os pais não escolheriam a sala porque eles já conviviam com essa realidade e que nunca ocorreu troca de turma por causa do professor. Mas isso se deve ao fato de que ele já tem uma história, tem experiência e já "provou" ser capaz de atuar no contexto educacional. Quando, porém, os professores são novos, os pais ficam com receio e não querem. $\mathrm{Ou}$ seja, essa aceitação se deve à trajetória do professor e, no caso dos professores iniciantes, certamente a vigilância se torna redobrada, sendo então necessário provar que esses docentes não oferecem riscos às crianças. A gestora municipal GM.EI falou claramente que os pais escolheriam a figura feminina, porque, segundo ela, as mulheres demonstram mais afetividade, compreensão e dedicação, enquanto os homens são mais ríspidos e menos acolhedores. Para ela, só pelo fato de a professora ser do sexo feminino, os pais esperam que as crianças sejam tratadas com mais carinho e atenção.

Quando questionada, a F1.EI disse, de maneira breve, que a escola decidiu e ela aceitou. A F2.EI, inicialmente, declarou não ter nenhuma escolha e que, para ela, tanto fazia. No entanto, em seguida, ela complementou: "Se ele é homem ou não, depende, vai depender também do professor, né? Se for professor, assim, que nem o professor J., que é paciente [...] Agora, se for daqueles professor grosseirão, daí já não dá, né?".

Tanto as gestoras quanto os familiares evidenciaram a preferência pela professora mulher, pelo conceito de que ela é mais carinhosa, receptiva, amorosa e caracterizaram o homem como ríspido, rude. Tais ideias demonstram as 
representações da sociedade de que são as mulheres que devem cuidar da educação das crianças, de que um homem também pode ser aceito, porém tal proeza acontece depois que esse profissional prova que não oferece riscos às crianças. Isso, provavelmente, torna difícil a vida de professores homens iniciantes na docência. A respeito dessa temática, Rocha (2012) assegura:

O binarismo feminino/masculino é recorrente nas pesquisas, evidenciando que a sociedade ainda pensa o mundo de forma excludente e preconceituosa quando, por exemplo, associa ao homem a ideia de masculinidade ligada ao provedor, forte, rude, disciplinador e à mulher a noção de feminino, condizente com uma pessoa boa, carinhosa, maternal e redentora. Indo um pouco mais além nestas reflexões poderíamos ainda completar que homens são vistos como sexuados, perversos, que estão sempre à procura de uma vítima para satisfazerem seus desejos ligados à sexualidade e que as mulheres seriam dotadas de uma assexualidade incomum, tornando-as puras, quase santas, o que as tornaria pessoas acima de qualquer suspeita (ROCHA, 2012, p. 8).

Um fato relevante se deu quando a gerente municipal afirmou que não houve nenhuma mudança na rotina da instituição com a chegada do professor homem, porém a gestora da escola disse que havia apenas meninos estudando na sala do professor. No viés das representações sociais, o "normal" naquela instituição era ter professoras mulheres, mas, com a mudança na gestão escolar, ocorreu um choque, um estranhamento ao presenciar um professor homem. Logo se buscou uma forma para amenizar a situação, ou seja, organizar o local. Assim, matricularam apenas meninos na sala do professor, modificando a organização da instituição de educação infantil para não haver a preocupação em ter meninas convivendo diretamente com um docente do gênero masculino. Em uma das falas da GE.EI, quando questionada sobre se deveria aumentar o número de professores homens, ela argumentou:

\footnotetext{
"Olha, eu acho que não, e isso é pessoal. Porque na verdade também é bastante difícil, porque as pessoas não são iguais. Nós conseguimos trabalhar bem com o professor J. porque ele tem todas as características dele, porque nem todo profissional é assim. [...] Por ser criança muito pequena, né? Por exemplo, se você aumentar o número de homens, é complicado, né? Porque as pessoas veem muito na educação infantil a presença feminina. Não é discriminação do homem, não é nada, é que vocês estão num sistema, né? Isso vem de muitos anos atrás, sim, não que eles não façam um bom trabalho. Com certeza, ele é o segundo professor que eu conheço que faz um bom trabalho nessa área. Mas, assim, é a questão do momento e você tem que conversar com a equipe toda." (GE.EI)
}

De forma geral, é possível confirmar que o trabalho do homem professor na educação infantil é um fato que causa diversas opiniões. No caso dos participantes da pesquisa, fica nítido que, apesar do respeito desenvolvido pelo professor, sempre há um receio, e as pessoas ficam incomodadas ou desconfortáveis com essa situação. Isso se deve a um determinado conceito que a sociedade sobrepôs à docência na educação infantil, de que a mulher é educadora nata, carinhosa e perfeita. Então, quando encontram um homem, imaginam que esses profissionais não estão em seu lugar. Isso se deve às representações sociais, que, segundo Oliveira e Werba (2003), são responsáveis por pressionar a pessoa no meio em que vive, com o objetivo de moldar a sua conduta e expressar suas contradições. Assim, uma representação social organiza e transforma o ambiente para que a conduta sempre se conserve. A higiene e o cuidado com o corpo da criança aparenta ser a principal preocupação dos envolvidos, devido ao fato de que a mulher é idealizada como a educadora "perfeita" para esse papel. Todavia, não há problemas envolvendo professores homens na educação infantil, existe apenas o cuidado e a vigilância constante em relação a esses profissionais.

\section{Ensino fundamental}

Para que fossem analisadas as representações dos participantes da pesquisa, utilizou-se a mesma técnica da educação infantil, em que foram levantadas indagações ao gestor, ao professor e às famílias de crianças que estudam com o docente do gênero masculino. Foram questões relativas ao trabalho desenvolvido pelo professor homem nos anos iniciais do ensino fundamental.

Atuante há 14 anos como professor, o PH.EF afirmou que cresceu muito com sua trajetória em sala de aula, destacando alguns pontos positivos e outros negativos sobre esse trabalho:

\footnotetext{
“Os positivos, assim, eu como professor, agora eu estou há 14 anos já, eu cresci muito. Assim, eu vejo que o professor homem, em sala, ainda tem mais aquele... impõe mais porque eles [alunos] têm respeito, eles têm medo da voz do homem e... o ponto negativo, assim, os pais não ajudam a gente. Você conversa com os pais e muitos não entendem, muitos acham, por exemplo, que você vai reclamar da filha. No começo... aqui não, eu não tive receio, eles batiam de frente e eu conversava com eles. Aqui eu consegui, graças a Deus, colocar a minha sala... A minha sala é numerosa, na minha sala tem bastante meninos também e eu não gosto que o aluno fique em cima de mim, não gosto que fique... Porque eu já tive em outras escolas trabalhando, que foram casos assim, eu não gosto de alunos que ficam.. Também não sou também: “Ah, ele é carrasco!”. Não. Eu sou carinhoso, eu abraço, eu cumprimento tudinho, mas assim, tudo no respeito como professor." (PH.EF)
} 
O PH.EF ressaltou que o professor homem impõe mais autoridade e respeito. Ele também afirmou que muitos dos pais não entendem quando ele chama a atenção dos alunos, porém não teve receio e assim conseguiu montar sua sala, ou seja, conquistou seu lugar no meio escolar. Também abordou o relacionamento professor/aluno. Fonseca (2011) adverte que, desde a entrada e a continuidade do professor homem na escola, desencadeia-se uma série de comportamentos, atitudes e vigias de mentes e corpos, sendo esperado do profissional que atua nos anos iniciais carinho, paciência e afeto. Ele ainda diz que "[...] espera-se da professora dos anos iniciais carinho e afeto, até mesmo carinho físico. Mas e dos professores homens dos anos iniciais? Estes acabam por se submeter a subterfúgios e formas de controle, objetivando reduzir o contato físico" (FONSECA, 2011, p. 49). No caso do professor entrevistado, ele mesmo evidencia receio do contato físico com o aluno, devido a algumas experiências que já teve e pela preocupação de que haja algum subtendido.

A respeito desse assunto, o GE.EF mencionou que se defrontou com uma situação em que um professor teve problemas pela questão de aproximação com alunas: "[...] ele falou assim: Diante dessa situação, eu acho que vou ter que mudar até o meu modo de ser". Quando questionado se havia ocorrido algum caso parecido com professoras mulheres, o GE.EF argumentou que não e justificou dizendo que seria "normal" a menina ter paixão platônica pelo professor. No entanto, o docente deve saber se posicionar diante de tal situação. Nos dois casos e independentemente do sexo do professor, essas questões acontecem no cotidiano escolar. Quando, porém, trata-se da mulher, então não se veem problemas em ter contato com a criança, pois ela é vista como assexuada e pura, conforme relata Kulesza (2005, p.4):

[...] mesmo quando o lado sedutor da professora é cantado, reconhecido, ele é rapidamente oculto e subjugado pelo seu lado civilizador. As representações da mulher professora, visivelmente sensuais e prenhes de pulsões libidinais, são diretamente opostas àquelas das quais emana uma aura de santidade, de pureza, de perfectibilidade moral, consideradas ideais para o exercício do magistério no ideário republicano.

Cabe ressaltar que a postura do professor em sala de aula, independentemente do gênero, deve ser baseada em respeito. Em relação aos pontos positivos e negativos da atuação do professor homem, a F1.EF expôs: “[...] com relação à minha filha, foi muito bom. Ele é pulso firme, sabe disciplinar, não é daqueles que só passa a mão na cabeça da criança, tem disciplina e, assim, negativo, assim... porque a criança estressa mesmo". O F3.EF ressaltou que teve professor homem quando pequeno e sempre gostou, não vendo problemas na atuação desses profissionais. Segundo ele, "[...] professora mulher, ela ensina, né? Mas pra falar da parte que nós homens, quando adquire certa idade, é mais fácil pro homem falar direto pro menino, né? Pro rapaz. Então tem certos momentos que é bom professora mulher e certos momentos que é bom professor homem". O F2.EF deixou transparecer suas representações a respeito do assunto quando afirmou:

“[...] minha grande preocupação é que eles são voláteis, nós somos voláteis, a gente perde o controle muito rápido, não adianta... Então é estranho. Se a G. [criança] chegar em casa reclamando de alguma coisa, eu vou perguntar diretamente pra ele [professor]. Não vai ser lá pro diretor não, tá entendendo? Por isso eu não gosto muito, mas eles são de boa, esses dois que ela [criança] está tendo contato, são de boa, normal. Agora eu prefiro mais mulher, não adianta.” (F2.EF)

Nos dois primeiros casos, aparentemente não houve nenhum ponto negativo, definindo o professor homem como pulso firme, que sabe impor e disciplinar as crianças. Já o F2.EF disse que, apesar de os professores da filha serem tranquilos, não esconde de ninguém que sua preferência é por mulheres. Todos esses conceitos atribuídos à docência nos anos iniciais do ensino fundamental estão relacionados às representações da sociedade, que são responsáveis por "organizá-la" e moldá-la de acordo com os ideais determinantes. Essas representações estão também presentes na em outras pesquisas:

As representações sociais predominantes, evidenciadas por meio dos relatos dos familiares, são de que as mulheres têm maiores habilidades para trabalhar com as crianças pequenas, principalmente com as meninas, e de que os homens professores impõem mais respeito, tanto pelo seu estilo de voz, quanto pela sua postura firme e impositiva (GONÇALVES; CAPRISCO; FERREIRA, 2015 p. 151).

$\mathrm{Na}$ questão seguinte, os participantes foram questionados sobre sua opinião a respeito do trabalho desenvolvido pelo professor homem nos anos iniciais do ensino fundamental. O GE.EF afirmou que achou essa ideia interessante: "Eu vejo, comigo, não sei por parte de algumas mães, algumas pessoas têm um certo receio, né? Não sei se é um preconceito em relação a isso, porque a gente sempre tá acostumado a ver mulheres atuar nesse cargo". Algo questionador é o GE.EF, por ser um professor homem, e as pessoas estarem acostumadas a ver mulheres atuar nesse cargo. Porém isso se deve ao fato de que ele sempre atuou em sala de aula do $6^{\circ}$ ao $9^{\circ}$ ano, sendo algo novo para o mesmo ver professores homens na educação de crianças menores. 
Na mesma fala, no entanto, também ressaltou que não havia problemas no trabalho desses profissionais: "Eu acredito que não tem... porque são professores experientes, porque são regentes, são professores que já tão há anos na rede". Como anteriormente foi colocado, isso se trata do período comprobatório pelo qual os professores homens passam, e depois de muito tempo de "vigilância", ganham a confiança e provam que não oferecem riscos às crianças. Assim, esse mesmo período de teste a professora do gênero feminino não precisa enfrentar, pelo conceito estabelecido de que a mulher é o ser ideal para trabalhar com crianças. Algo que foi construído historicamente. "A concepção de que a mulher é a melhor educadora para crianças pequenas foi absorvida pela sociedade. Trata-se de representações sociais que contribuíram para o afastamento dos homens do magistério e para o aumento da participação feminina no ambiente escolar" (FARIA; GONÇALVES, 2015, p. 6).

Em referência à mesma questão, os familiares das crianças responderam sobre a opinião relativa ao trabalho desenvolvido por professores homens nos anos iniciais do ensino fundamental. O F3.EF declarou que o estudo estava sendo aperfeiçoado e que antigamente essa tarefa aparentava ser só para mulher; no entanto, o homem já estava complementando esse lado e, hoje em dia, não existe trabalho específico para homem e mulher. A F1.EF disse que achava bom e muito interessante, pelo carinho, respeito, educação e disciplina que o professor tinha com as crianças. Segundo ela, o professor tinha pulso firme e isso ajudava muito.

Já o F2.EF, primeiramente, argumentou que achava normal, não vendo nenhuma novidade, e que o ser humano é capaz de lecionar para qualquer um. Em seguida, ele expôs sua opinião verdadeira: "Vou falar pra você: homem é mais difícil de trabalhar, não tem muita paciência. Eu acho que homem, pra mim, não é bom não, pra mim, não é, não tem..., não serve pra lecionar. Pra mim, particularmente, eu acho que não". Quando perguntado sobre o porquê dessa sua posição, ele assim respondeu:

\footnotetext{
"Tem certas situações que ele não vai saber resolver. Porque têm muitas meninas, menina é mais diferente do que guri, então tem coisas que ela fala, que você está entendendo, mas não. Nada contra, mas eu sou mais mulher do que homem. Em minha vida inteirinha, só tive um professor homem, o professor B., só. Mas ele era um cara quieto, mas a gente sabia da vida dele: ia pro baile, bebia, tomava cachaça, fumava, nós víamos que ele era um cara totalmente instável, tá ligado? Qualquer coisinha, acho que ele estava bravo, ficava bravo... Por isso que eu, desde aquela época que eu tive contato com ele, foi desse jeito, e eu não gostei, entendeu? Então acho que eles são instáveis,
}

eles... entendeu? Eles são mais agressivos também, e criança, se tá ligado? É espoleta, se tá entendendo? Pode acontecer alguma coisa, mas não por causa do... [professor], ele pode perder o controle. Já mulher não, mulher já manda tirar da sala, é mais tranquila." (F2.EF)

Essa ideia de que o homem é instável, agressivo, sem controle e "perigoso" para trabalhar com crianças é algo que foi construído culturalmente. Entretanto, algumas pesquisas revelam que a mulher é grande causadora de violência psicológica na educação, sendo que esta acontece e independe do gênero do professor, estando relacionada às práticas desenvolvidas em sala de aula que acabam por deixar lembranças negativas nos estudantes. Estudos realizados por Koehler (2003, p. 10) apontaram: “O 'pior professor' eleito pelos alunos, 70,9\% pertencem ao gênero feminino e $29,1 \%$ ao gênero masculino. No entanto, devemos considerar que, historicamente, já há algumas décadas, a maioria dos professores é do gênero feminino".

Ou seja, essa estatística de $70,9 \%$ versus $29,1 \%$ pode ser explicada pelo fato de haver mais mulheres na educação do que homens e, na maioria dos casos, docentes do gênero feminino também não são dóceis e tranquilas, são seres humanos e estão sujeitas ao estresse no dia a dia, algo que também é transmitido para as crianças. Segundo Koehler (2003), no decorrer do tempo, a mulher vem recebendo diversas atribuições, tais como babá, doméstica, submissa e continua se responsabilizando por organizar a casa e se encarregar da educação dos seus filhos e dos filhos dos outros, sendo também sujeita à resignação, à subordinação, e não sujeita à política, à liderança, entre outros aspectos que estão presentes na mente e nos costumes da sociedade. Desse modo:

\section{Legitima-se assim, a mulher-professora, uma profissão inerente à condição de mulher na tarefa de educar. A mulher submissa e subjugada ao homem, ao macho, ao marido, reproduz a relação assimétrica de poder na figura da professora. Surge a mulher mandona, que faz do ambiente escolar uma 'extensão do ambiente doméstico'. Esta mulher professora que grita, humilha, envergonha, ameaça, ridiculariza, comete injustiças, enfim, reproduz com crianças e adolescentes os ATOS de Violência que, durante séculos, vem sofrendo no âmbito doméstico (KOEHLER, 2003, p. 10).}

Na sequência, os participantes foram inquiridos sobre qual seria sua opção na hipótese de haver duas turmas do mesmo ano do ensino fundamental, uma comandada por professor homem e outra por professora mulher. O GE.EF acrescentou que há algum tempo poderia acontecer isso, porém dependia da qualidade do professor no ensino fundamental, porque, se fosse na pré-escola, seria uma 
preocupação ter um regente homem: “[...] na pré-escola, eu acho que tem mais essa questão, é a primeira vez que [a criança] tá entrando na escola, né? Então é cuidado. E é até complicado, às vezes, a questão da confiança dos pais, eles podem pensar: 'Ah, é um homem que tá aqui!', né? Entendeu?".

O F2.EF confirmou que escolheria a mulher, pois, a seu ver, elas ensinam mais, e assim justifica: “[...] a mulher é mais delicada, mulher é mais tudo, é mais mãe, né? Homem não tem isso, homem é desnaturado, homem é preocupado com outras coisas porque tem que ser". A F1.EF afirmou que não escolheria, mas depende da situação: "Não, só se eu soubesse uma coisa dele, aí já é outra coisa, mas, assim quando o diretor contrata, ele faz uma reunião, chama todos os pais e conversa, explica quem é, apresenta o professor, né? O currículo do professor". Já o F3.EF ressaltou que não haveria escolha, pois não há profissão específica para homem e mulher.

Segundo o professor homem entrevistado, PH.EF, os familiares não fariam nenhuma escolha. Ele reconheceu que são exigentes, mas que a realização de um bom trabalho não depende do sexo do profissional.

\begin{abstract}
"Por incrível que pareça, eu acho que não [escolheriam sala de homem ou mulher]. Muitos pais aqui me elogiam muito, falam que o filho estudava no outro colégio e era fraco. Eu pego... Eu pego no pé! Eu pego no pé, sabe por quê? Porque como a escola pega no pé da gente e a escola pega porque é muita cobrança. A nossa técnica, ela vem direto aqui e pega também. Assim, eu tenho alguém pra obedecer. Então eu tenho que cumprir a minha [função], independente se é homem ou se é mulher, eu tenho que cumprir o meu planejamento." (PH.EF)
\end{abstract}

Todas essas falas acima descrevem as representações sociais nas quais cada um define aquilo que lhes parece "certo". Esses conceitos são transmitidos de geração em geração e, quando fogem do padrão a que estão costumadas, as pessoas reagem com desconfiança e estranheza. Fonseca (2011), no entanto, relata sobre sua própria trajetória como professor, destacando uma reportagem publicada em uma revista.

A revista concluiu que temos tanta capacidade quanto as demais professoras, além de conseguir 'brincar e impor limites na dose e hora certas'. A revista ainda informa que, nos anos iniciais, representamos $16,5 \%$ do total de professores no país. Através desta reportagem, tive contato, por correspondência (carta e e-mail), com outros professores que compartilharam comigo a angústia de, a todo tempo, termos que provar (e conseguir) a nossa capacidade num segmento que, historicamente e discursivamente, pertence às mulheres (FONSECA, 2011, p. 10).
Acima de tudo, deve ser levado em consideração que todo profissional formado e bem preparado é capaz de exercer sua profissão independentemente do seu gênero, inclusive na área da educação.

\section{CONSIDERAÇÕES FINAIS}

A pesquisa realizada teve por intuito identificar as representações sociais predominantes em professores homens, em gestores escolares e em familiares de alunos de educação infantil e anos iniciais do ensino fundamental do município de Corumbá (MS), em relação ao trabalho educativo desenvolvido por docentes do gênero masculino com crianças. Ficou evidenciado que a presença do homem nas duas primeiras etapas da educação básica ainda é alvo de muitos tabus. Geralmente ocorre a "vigilância" em relação aos docentes do gênero masculino, havendo a necessidade de conhecer, analisar e investigar a vida desses profissionais, fato que não acontece com professoras mulheres.

Mas a grande questão na educação infantil é o cuidado/higiene, pois existe muito receio de o professor limpar e dar banho nas crianças, e a escola buscou utilizar a auxiliar (ajudante) para a realização da tarefa, com o intuito de amenizar os possíveis conflitos. Já no ensino fundamental, o medo do contato físico e o receio do professor de ensinar a menina são características que marcam a vida do profissional da educação que opta por trabalhar com crianças. Nos dois níveis de ensino averiguados, não há problemas relacionados ao trabalho desenvolvido pelos professores homens; no entanto, o medo do que a família vai pensar e a ideia de que a mulher é única e ideal para cuidar e educar as crianças contribui para que continue reduzido o número de docentes do gênero masculino trabalhando nessas duas etapas da educação básica. Todas essas convicções estão relacionadas às representações da sociedade, que atualmente não concebe a ideia de o homem contribuir com a educação escolar de crianças, mas não há nada que não possa ser transformado. Vai depender da sociedade e de como ela se desenvolve com o passar do tempo.

\section{REFERÊNCIAS}

ARCE. A. Documentação oficial e o mito da educadora nata na educação infantil. Cadernos de Pesquisa, n. 113, p. 167-184, jul. 2001.

BONI, V.; QUARESMA, S. J. Aprendendo a entrevistar: como fazer entrevistas em Ciências Sociais. Revista Eletrônica dos Pós-Graduandos em Sociologia Política da UFSC, v. 2, n. 1, p. 68-80, jan./jul. 2005.

COELHO, S. M. P. F.; CARLOTO, C. M. Violência doméstica, homens e masculinidades. Textos \& Contextos, Porto Alegre, v. 6, n. 2, p. 395-409, jul./dez. 2007. 
CONGRO, C. R. Análise do perfil e da satisfação dos turistas da cidade de Corumbá (MS) visando à adequação dos empreendimentos turísticos da região. Dissertação (Mestrado em Turismo e Hotelaria) - Universidade do Vale do Itajaí, Balneário Camboriú, 2005.

CONNELL, R. W. Masculinities. Berkeley: University of California Press, 1995.

FARIA, Adriana Horta de; GONÇALVES, Josiane Peres. Famílias, reações de gênero e representações sociais. Psicopedagogia [On-line], 2015. Disponível em: <http:// www.psicopedagogia.com.br/new1_artigo.asp?entrID=1850\#. V1V5pDUrLIX>. Acesso em: 20 maio 2016.

FONSECA, T. S. M. Quem é o professor homem dos anos iniciais? Discursos, representações e relações de gênero. Dissertação (Mestrado em Educação) - Universidade Federal de Juiz de Fora, 2011.

GONÇALVES, J. P.; CAPRISCO, Z. R. N.; FERREIRA, V. C. M. Professores homens na educação infantil: aceitação e receio dos familiares que vivenciam essa experiência. Pesquisa em Foco, São Luís, v. 20, n. 2, p. 136-154, 2015.

IBGE - Instituto Brasileiro de Geografia e estatística. Mato Grosso do Sul - Corumbá. Disponível em: <http://cod.ibge. gov.br/fdm>. Acesso em: 27 jan. 2016.

JARDIM, S. R. M. Gênero e educação: abordagens e concepções em dissertações de mestrado no Estado de São Paulo. 122 f. Dissertação (Mestrado em Educação) - Centro de Educação e Ciências Humanas da Universidade Federal de São Carlos - UFScar, São Carlos, 2003.

KOEHLER, S. M. F. Violência psicológica: um estudo do fenômeno na relação professor-aluno. Anais do Congresso La Nueva Alfabetización: un reto para la educación del siglo XXI. Madrid, 2003.

KULESZA, W. A. A sedução da professora. Anais do IX Simpósio Internacional Processo Civilizador Tecnologia e Civilização. Ponta Grossa, Paraná, Brasil, 2005.

LOURO, G. L. Gênero, sexualidade e educação: uma perspectiva pós-estruturalista, 10. ed. Petrópolis, RJ: Vozes, 1999.

MOSCOVICI, S. A social psychological analysis. London: Academic Press, 1973.

OLIVEIRA, F. O; WERBA, G. C. Representações sociais. In: OLIVEIRA, F. (org.). Psicologia social contemporânea. Petrópolis, RJ: Vozes, 2003. p. 104-117.
PINCINATO, D. A. V. História do magistério: experiências masculinas na carreira administrativa no Estado de São Paulo (1950-1980). In: REUNIÃO DA ASSOCIAÇÃO NACIONAL DE PÓS-GRADUAÇÃO E PESQUISA EM EDUCAÇÃO, 27. 2004, Caxambu. Anais eletrônicos. Rio de Janeiro: Anped, 2004.

RABELO, Amanda Oliveira O. Professores discriminados: um estudo sobre os docentes do sexo masculino nas séries do ensino fundamental. Educação e Pesquisa, São Paulo, v. 39, n. 4, p.907-925, out./dez. 2013.

RAMOS, J. Um estudo sobre os professores homens da educação infantil e as relações de gênero na rede municipal de Belo Horizonte-MG. 139 f., 2011. Tese (Doutorado em Educação) - Pontifícia Universidade Católica de Minas Gerais, PUC/MG. Disponível em: <http://www. biblioteca.pucminas. br/teses/Educacao_RamosJ_1.pdf>. Acesso em: 15 abr. 2016.

ROCHA, C. M. Homens podem ensinar crianças pequenas? A experiência masculina de ensino nas etapas iniciais da educação básica. Anais do VI Congresso Paulista de Educação Infantil - Copedi, São Paulo, Faculdade de Educação, USP, 2012.

SANTOS, W. T. M. Modelos de masculinidade na percepção de jovens homens de baixa renda. Barbarói, Santa Cruz do Sul, n. 27, p. 130-157, jul./dez. 2007.

SÁ, C. P. Representações sociais: o conceito e o estado atual da teoria. In: SPINK, M. J. (Org.). O conhecimento no cotidiano. São Paulo: Brasiliense, 1995. p. 19-45.

SCOTT, J. Gênero: uma categoria útil de análise histórica. Educação e Realidade, Porto Alegre, v. 2, n. 20, p.71-99, jul./dez. 1998.

TRINDADE, Z, N. Masculinidades, prática educativa e risco social. Simpósio Nacional de Psicologia Social e do Desenvolvimento. Anais do X Encontro Nacional ProcadPsicologia/Capes: Violência e Desenvolvimento Humano, 2005. p. 123-127.

VIANNA, C.; FINCO, D. Meninos e meninas na educação infantil: uma questão de gênero e poder. Cadernos Pagu, n. 33, p. 265-283, jul./dez. 2009.

ZANTEN, A. V. Pesquisa qualitativa em educação: pertinência, validez e generalização. Perspectiva, Florianópolis, v. 22, n. 1, p. 25-45, jan./jun. 2004.

Recebido em 26-06-2016 Aprovado em 15-02-2017. 